\title{
El urbanismo, la política y la economía (y viceversa). Una perspectiva comparada *
}

\section{Horacio Capel**}

\section{Resumen}

Se debate de qué forma la economía influye en la política (o interacciona con ella) y determina el tipo de urbanismo que se realiza, así como la cuestión de la posible influencia del urbanismo en la política y en la economía. La comparación entre España y Francia, y el desarrollo urbano y territorial en ambas naciones, permite encontrar numerosos puntos de contacto en su evolución. Se estudian sucesivamente: los cambios en los dos países, el marco legal estatal y regional y la necesidad de pensar el modelo de desarrollo urbano desde los problemas concretos que existen.

\section{Palabras clave}

Urbanismo en España; Urbanismo en Francia; Ciudades 1970-2010

\section{Abstract: Urbanism, politics and economy (and viceversa). A comparative approach}

This paper discusses how economics influence politics (or interact with them) and determine the kind of urban planning that is implemented. It also analyzes the possible influence of urban planning on politics and economics. A comparison between Spain and France and spatial development in both countries shows many common points in their evolution. The paper analyzes recent changes in both countries, the national and regional legal framework and the need to design the model of urban development on the basis of the specific problems that exist today.

\section{Key words}

Urban planning in Spain; Urban planning en France; Cities 1970-2010

\footnotetext{
* Con la autorización del autor se reproduce la conferencia/relatoría/reflexión de clausura del Coloquio "L'Urbanisme, la démocratie et le marché. Une experience espagnole (1975-2010)", del Institut d'Urbanisme de Paris, celebrado en Créteil, 15 y 16 de marzo de 2010 (ya recogida en Biblio 3W. Revista Bibliográfica de Geografía y Ciencias Sociales, Vol. XV, n 893, 25 de octubre de 2010).

** Catedrático de Geografía Humana, Facultad de Geografía e Historia, Universidad de Barcelona. Montalegre, 6, 0800 Barcelona. Email: hcapel@ub.edu
} 
Es un reto realizar una conclusión a las presentaciones y los debates de estas jornadas tan densas, desarrolladas en el Institut d'Urbanisme de Paris durante dos intensos días. Un Coloquio muy bien organizado por Laurent Coudroy de Lille, Céline Vaz y Charlotte Vorms, así como, de manera más general, por el Institut d'Urbanisme de París. Se trata de un Coloquio internacional, hispanofrancés, sobre un problema español. Siguiendo en ello una tradición francesa bien asentada, y apoyada, como en otros casos, por la Casa Velázquez. Una oportunidad para el diálogo hispanofrancés y el intercambio de los investigadores españoles y franceses, sobre un tema de interés común, referido a España. No tanto para comparar la evolución hispana y francesa, lo que también sería importante, y a lo que me referiré más adelante.

Confieso que estoy aquí con un poco de incomodidad. No me gusta nada hablar de los problemas de España en el extranjero, especialmente si no hay reciprocidad y no hablamos de los problemas del otro país, aunque solo sea para comparar. Acepté finalmente por la amistad y el aprecio que tengo por los organizadores de este Coloquio. El congreso ha permitido algunas comparaciones, tanto por las comunicaciones presentadas como por las visitas que hemos realizado a barrios del interior y de la periferia de Paris.

Con mucha frecuencia los científicos sociales que recibimos en España y que estudian nuestros problemas tienen una actitud crítica ante las cuestiones que estudian, lo que nosotros apreciamos mucho. Pero, con la edad, a veces uno desearía que los exámenes críticos que los geógrafos y científicos sociales franceses realizan sobre otros países, entre ellos España, pero sobre todo los países extra-europeos, se dirijan también hacia su propio país. En esos países extranjeros los autores franceses (como los ingleses o norteamericanos) pueden encontrar fácilmente el apoyo de estudios rea- lizados por investigadores locales críticos, e incluso hipercríticos, con su propia realidad, que son utilizados ampliamente para adoptar posiciones "progresistas" que tienen, generalmente, prestigio y buena acogida en su país de origen, siempre que no se dirijan hacia el interior.

También se echa en falta en ocasiones que los mismos estudios críticos que existen en Francia tuvieran mayor difusión en el campo de las ciencias sociales, especialmente en los medios académicos. Puede ocurrir que sean más conocidos y citados en el exterior que en los medios universitarios franceses, en ocasiones profundamente conservadores y autosatisfechos.

El objetivo del tema general L'urbanisme, la démocratie et le marché: une expérience espagnole (1970-2010) se entiende inmediatamente. Trata de reflexionar sobre los cambios que se han producido en el urbanismo español a partir de la recuperación de la democracia y en relación con el mercado inmobiliario. Tal como se dice en la convocatoria del Coloquio, "la evolución reciente de las ciudades españolas ha despertado mucha curiosidad en el resto de Europa desde la crisis inmobiliaria y bancaria desencadenada en 2007". Se me ocurre que habría sido interesante convocar este Coloquio a comienzos de la década, cuando el desarrollo español despertaba admiración en muchos países, entre ellos, y de forma principal, Francia. En los momentos en que ahora se realiza no debería despertar curiosidad, sino inquietud y, más aún, miedo; al igual que la evolución que han experimentado las ciudades y el mercado inmobiliario en Estados Unidos, en Gran Bretaña y en otros lugares, entre los cuales Francia. Miedo por la avaricia de empresarios y banqueros, por la escasa pericia de los economistas para anticipar la evolución, por la ineptitud de las autoridades políticas nacionales y europeas para regular el mercado, por la incapacidad de los ciudadanos para imaginar que el precio de la vivienda y del suelo 
podían caer. Y de manera más general, miedo por los graves conflictos sociales que pueden avecinarse ante la incapacidad del sistema económico de producir vivienda en condiciones adecuadas para las clases populares, por las desigualdades sociales que se mantienen en las ciudades y, especialmente, en las grandes áreas metropolitanas, por el enclaustramiento de las clases privilegiadas en barrios cerrados protegidos, por el gasto de energía, por la presión hacia el consumo, por el despilfarro general, y por vivir todos alegremente y de forma irresponsable por encima de nuestras posibilidades (los que vivimos así en los países desarrollados).

$Y$, de forma aún más general, por la generalización que parece existir de la corrupción en el urbanismo. Son frecuentes en la prensa las noticias como ésta:

"En el centro de todos los debates está el alcalde del municipio de (...), su primera adjunta (..$)$, encargada del urbanismo y antigua propietaria de una agencia inmobiliaria... y (...), el hijo de esta última, que gestiona la agencia familiar y que, por su parte, es también promotor".

A lo cual va unida la siguiente denuncia:

"la madre firmaba los permisos de construir para que el hijo pudiera vender sus parcelas, mientras que la empresa de camiones del alcalde transportaba los escombros y todo el mundo sabía que los terrenos eran inundables".

Un ejemplo escandaloso de prácticas corruptas en relación con el urbanismo. Hemos leído muchas similares en España, en los últimos años. Sólo que la noticia que damos es de Francia: pertenece a la inundación en el municipio de la Faute-sur Mer, en el departamento de la Vandée, como consecuencia del paso del huracán Xynthia el 28 de febrero de 2010, y apareció publicada en la prensa de París hace dos días, el 14 de marzo de $2010^{1}$.

1 Le Parisien-Dimanche, 14 de mars 2010, p. 12. La noticia dice así: "Au centre de toutes les discussions, le maire de la commune, René Marratier, sa première adjointe, Françoise Babin, chargée de l'urbanisme et ancienne propriétaire d'une
Tal como yo lo percibo, el Coloquio que hemos celebrado ha tratado de poner énfasis, desde una perspectiva general, en las relaciones entre el urbanismo, el marco político y la coyuntura económica. Tal vez el problema debería plantearse (dudo en escribir si también, o de forma prioritaria) en sentido inverso. Es decir de qué forma el mercado, es decir la economía, influye en la política (o interacciona con ella) y determina el tipo de urbanismo que se realiza. Parece claro que las variables urbanísticas son aquí las dependientes. Aunque asimismo deberíamos plantear la cuestión de la posible influencia del urbanismo (y la construcción) en la política y en la economía, aspecto éste especialmente relevante en el caso español, como seguramente en el francés (si hemos de creer a Chistian Topalov, Alain Lipietz y otros estudiosos del mercado inmobiliario, que se han planteado hasta qué punto la esfera de la producción económica contribuye a modelar el marco institucional y legal y si éste llega a estar subordinado al proceso de acumulación capitalistas, como se ha pretendido desde la perspectiva marxista).

Teniendo en cuenta los objetivos del Coloquio, las comunicaciones han tratado generalmente situaciones concretas. No son muchas las que han abordado los problemas generales, aunque puedan encontrarse algunas alusiones a ellos. En uno de los trabajos, y con referencia a la evolución política española desde la transición, se observa críticamente que "lógica de mercado y democracia no se oponen siempre" (Baron-Yeyes, 2010). No me parece una buena manera de plantear el problema. Debemos proponer la cuestión de manera más general, y creo oportuno señalar que no tienen por qué oponerse. Ni en España ni en Francia (a no ser que se afirme que en este sentido son

agence immobilière fautaise, et Philippe, le fils de cette dernière, que a repris l'agence familiale, promoteur par ailleurs. ... La mère signait les permis de construire pour que le fils puisse vendre ses lotissements, tandis que l'entreprise de camions du maire transportait les remblaiements et que tout le monde savait que les terrais étaient submersibles". 
dos países diferentes). En realidad, los marcos políticos en los que nos movemos en ambos países aceptan claramente la lógica del mercado. La Constitución Española de 1978 en su artículo 38 reconoce de forma explícita "la libertad de empresa en el marco de la economía de mercado"; y añade: "los poderes públicos garantizan y protegen su ejercicio y la defensa de la productividad, de acuerdo con las exigencias de la economía general y, en su caso, de la planificación".

Por tanto la lógica del mercado es, como punto de partida, un principio económico fundamental en nuestros países. $Y$, además, normalmente se valora la concertación público-privada, que es un aspecto destacado de las políticas públicas en muchos países democráticos, de manera general $\mathrm{y}$, especialmente, durante esta época reciente en que han dominado las políticas neoliberales.

Tal vez deberíamos plantear de entrada una cuestión general, para estudiar en España y en Francia: cuál es la lógica que relaciona el mercado (el sistema económico, la economía de mercado), el marco institucional y político, y el urbanismo. También debemos preguntarnos sobre cómo han cambiado esas relaciones con la evolución económica, es decir en las distintas fases de la evolución del capitalismo; y especialmente cómo han cambiado tras la crisis de 1973, y con la difusión de los principios neoliberales y de otros cambios significativos a los que se alude en los estudios realizados en los últimos años (sobre postindustrialización, postfordismo y otros). También podemos preguntarnos de qué manera la caída del muro de Berlín y la descomposición de los sistemas políticos socialistas han magnificado el sistema capitalista, dejándolo como la única alternativa económica posible.

Todavía, más allá de ello, podemos preguntarnos cuál debería ser la relación entre el mercado, el marco institucional y el urbanismo, qué sistema económico y político consideramos deseable, y explicitar en qué ciudad estamos pensando cada uno de nosotros.

En lo que se refiere a la comparación entre España y Francia, y el desarrollo territorial en ambas naciones, deberíamos plantear un problema general. Si resultara, como algunos estudios parecen dar por supuesto, o concluyen, que en los últimos treinta años la evolución ha sido muy diferente en uno y otro país (y en otros países democráticos, como los iberoamericanos), eso nos debería llevar a examinar -una vez más, y sobre nuevas bases teóricas- la cuestión de la relación del sistema económico general con la política. Deberíamos discutir porqué habría un capitalismo más benéfico y otros capitalismos depredadores, cual es la relación entre sistema económico y legislación, y cómo se articula dicha relación. También si la legislación es más capaz de domeñar y contener a los capitalistas en unos lugares que en otros; lo que sería especialmente valioso para reflexionar sobre la autonomía y la función de la política.

Ya sabemos que el capitalismo evoluciona. Pero deberíamos profundizar en la cuestión de si hay un capitalismo o varios simultáneamente; y si debemos discutir sobre el capitalismo, sobre los capitalismos o sobre los capitalistas.

\section{Cambios en el mundo y en España}

Muchas cosas han sucedido en el mundo y en Europa desde 1970: crisis de 1973; reestructuración del capitalismo; innovaciones en las comunicaciones terrestres, aéreas, marítimas; desarrollo de la ingeniería financiera; aparición de Internet y otros más. En España, transición política a la democracia, integración en la Unión Europea, crecimiento económico espectacular, haber pasado de ser un país de emigración a convertirse en un área receptora de inmigrantes europeos y extraeuropeos.

Desde el punto de vista del urbanismo deben señalarse los cambios urbanos, con la entrada en una fase de Urbanización Generalizada, las trans- 
formaciones en las áreas metropolitanas (Capel, 2003), con el debate sobre la ciudad dispersa y ciudad compacta o sobre el policentrismo, el crecimiento de la urbanización más intenso que el incremento demográfico, e incluso crecimiento físico en situaciones de estancamiento demográfico ${ }^{2}$. También debe aludirse al nuevo papel de las ciudades pequeñas y medias (Capel, 2009).

En estos años se ha producido el cuestionamiento del Movimiento Moderno en arquitectura y urbanismo, y ha habido cambios en las ideas aceptadas sobre el papel del planeamiento. En los años 1980, como resultado de la crisis económica, o de la desmesura de algunas proyecciones económicas y urbanísticas, apareció una crítica del planeamiento, una corriente "contra el plan". El énfasis en el proyecto urbano durante los años 80 tuvo una funcionalidad en esa situación en la que se cuestionaba la necesidad del planeamiento, de forma paralela a la difusión de las opciones políticas neoliberales.

Diez o quince años más tarde, a mediados de los años 1990 algunos urbanistas volvieron a hacer fuertes llamadas de atención sobre la necesidad de una nueva vuelta a la valoración positiva del planeamiento ${ }^{3}$.

\section{Necesidad de comparaciones entre España y Francia y entre los problemas urbanísticos de los dos países}

Especial interés puede tener hoy una comparación directa entre los problemas urbanísticos en España y Francia, problemas que están profundamente influidos por otros aspectos más generales de la estructura económica y social así como de la misma evolución histórica.

${ }^{2}$ Como ha señalado, con el análisis del caso de Vitoria, Ramón López de Lucio en este mismo Coloquio.

3 La revista Urban, fundada por Fernando de Terán en 1997, en el Departamento de Urbanística y Ordenación del Territorio de la Escuela Técnica Superior de Arquitectura de la Universidad Politécnica de Madrid, puede ser un buen exponente de esta nueva sensibilidad ante el planeamiento urbano.
Durante el franquismo el sentimiento de inferioridad de los españoles ante las democracias europeas más desarrolladas, entre las que se encontraba Francia, fue muy acusado. Aunque Francia y España habían tenido regímenes políticos hermanos (el régimen de Vichy y el franquismo), y conocieron problemas similares en la transición a la democracia, con treinta años de diferencia, no éramos conscientes de ello. $\mathrm{Y}$, al parecer, tampoco los franceses. Para los que sabíamos algo de la historia contemporánea francesa, nada había más molesto que las preguntas que en los años 1960 nos hacían los turistas franceses sobre el régimen de Franco y sobre nuestra incapacidad para quitárnoslo de encima, y la ignorancia que tenían, al mismo tiempo, sobre lo que había significado Vichy en Francia.

Hay, seguramente, bastantes diferencias entre España y Francia. Desde el punto de vista de sus consecuencias en el urbanismo, me interesa destacar algunas importantes.

Ante todo, el régimen de Vichy duró cuatro años, y el franquismo cuarenta.

No tuvimos la suerte de ser liberados por los ejércitos aliados al final de la Segunda Guerra Mundial, ni de que los restos del ejército republicano español (que se habían integrado en la Resistencia francesa, y que contribuyeron a la liberación de París el 26 de agosto de 1944), pudieran entrar en Madrid codo con codo con tropas del ejército francés.

Francia no tuvo que sufrir el exilio de una parte esencial de la intelectualidad y de los profesores universitarios (más de 800), que realizaron su trabajo en diferentes países, sobre todo americanos; algunos de ellos arquitectos vinculados al Movimiento Moderno y que podrían haber contribuido de forma destacada al debate urbanístico en nuestro país.

Tampoco nos beneficiamos del Plan Marshall, en

${ }^{4}$ http://www.derechos.org/nizkor/espana/doc/paris.html. 
unos años decisivos que aquí en Francia dieron paso a los Treinta Gloriosos. Frente a ello, desde el punto de vista económico solo tuvimos en España unos Diez Gloriosos, la década de 1960.

Pero sobre todo, las dos Francias, la progresista y la reaccionaria, que convivieron con tensiones tras el Edicto de Nantes y que se enfrentaron de forma aún más acusada después de la Revolution de 1789, aprendieron a convivir en el marco de una República laica. Esa Francia reaccionaria que intentaba, y en algún caso consiguió, restaurar el Ancien Régime, que tras la Comuna de 1871 se esforzó en poner orden en el sistema social, recristianizando el país, y que en el siglo $X X$ mostró su fuerte presencia con el nacionalismo de derechas representada por Action Française y el pensamiento de Charles Maurras, la que saludó con alegría la sublevación de Franco e influyó todo lo que pudo para asegurar la neutralidad del gobierno francés ante la guerra de España, permitiendo con ello la caída de la República, tuvo que aprender a convivir en el seno de un régimen republicano; un sistema político que en España quedó destruido en su mismo inicio por el enfrentamiento de las dos Españas que, según Antonio Machado, nos habían de helar el corazón.

Las comparaciones internacionales son necesarias. $Y$ deben hacerse una y otra vez, porque la relación con el pasado de una sociedad se modifica a lo largo del tiempo. Los cambios políticos y el curso de los sucesos afectan a la percepción de las actitudes y valoraciones seguidas en relación con un problema. Se ha señalado, con referencia a la evolución de Alemania que la percepción del periodo nazi ha podido cambiar con los años ${ }^{5}$. Durante las décadas de 1950 y 60 el fin de la Segunda Guerra Mundial y la reimplantación de la democracia, dicho periodo se percibió en Alemania como una cesura importante, el cambio de una épo-

${ }^{5}$ Como ha mostrado el historiador alemán Walter L. Bernecker 1998. ca. Tras la caída del muro de Berlín en 1989 la narración histórica ha podido experimentar modificaciones destacadas y han vuelto a señalarse, en cambio, algunas continuidades (por ejemplo, la continuidad de la sociedad alemana como sociedad industrial y moderna), a la vez que se han resaltado en la narración histórica otras cesuras, consideradas ahora igualmente relevantes (como la de los años 1957 a 67, cuando se daría el cambio de la sociedad industrial a la postindustrial).

De manera similar ha podido suceder en lo que se refiere al franquismo. En los años 1960 y 80 se ponía énfasis, sobre todo, en la interrupción del sistema democrático, en la diferencia que el franquismo introducía respecto al resto de Europa. Luego se fue descubriendo que, a pesar de las diferencias de sistema político, muchas cosas eran similares al resto de Europa, y que había gran número de semejanza y continuidades en las que no se había reparado. A partir de 1953, tras la firma de los pactos con Estados Unidos, Francia y España estábamos en el mismo bando, alineados por la Guerra Fría como satélites de Estados Unidos, frente a la URSS y los "países satélites" de más allá del telón de acero.

Hubo también continuidades en la legislación urbana, como la vigencia en algunos aspectos del Estatuto Municipal de 1924, a pesar de la anulación de muchas leyes republicanas ${ }^{6}$, la persistencia de rasgos de la arquitectura racionalista en la España franquista ${ }^{7}$, y la modernidad que en la época tuvo la Ley del Suelo de 1956.

Tanto en Francia como en España, el trauma de la transición política a la democracia se hizo con silencios y olvidos, con transacciones, y con la creación de mitos (la Resistencia en Francia y los Maquis en España), y tuvieron, años más tarde, evoluciones similares en lo que se refiere a la recupe-

\footnotetext{
${ }^{6}$ Véase en este sentido lo que sucedió en Sevilla en relación con las políticas de renovación urbana en las décadas de 1940 y 1950, Fernández Salinas 1992.

7 Como mostró Carlos Sambricio.
} 
ración de la memoria histórica (sobre las atrocidades del régimen de Vichy, y sobre las del franquismo, en los mismos años).

En todo caso, el retraso de treinta años en la recuperación de la democracia nos creaba a los españoles complejos de inferioridad. Habíamos llegado a creernos seriamente el eslogan acuñado por el Ministerio de Fraga Iribarne sobre "España es diferente", que circuló en Europa como Spain is different, y que tan eficaz fue para atraer el turismo europeo en los años 1960. Tardaríamos mucho en aceptar que España no es diferente, que es un país europeo que ha tenido una evolución muy parecida, con anticipaciones en algunos casos respecto a lo sucedido fuera, y con retrasos en otros. Y que Francia se parecía más a España de lo que nosotros imaginábamos.

Eso mismo sucedía en lo que se refiere a la percepción de los problemas urbanos. Tardamos en reconocer que el impacto del Movimiento Moderno fue comparable en España y en Francia, y que pudo dar lugar a parecidos debates, que los polígonos de viviendas españoles eran lo mismo que los grands ensembles, y que tenían idénticos problemas, y similares ventajas y defectos, al igual que sucedía en las ACTUR españolas y en las Villes nouvelles francesas. La crisis del urbanismo del movimiento moderno se dio en muchos países, entre ellos España y Francia, de forma prácticamente simultánea.

Podemos, por todo ello, afirmar que la construcción de las periferias urbanas se ha hecho durante estos treinta años de forma sensiblemente semejante en España y en Francia. En los dos países ha habido construcción de grands ensembles, áreas de vivienda unifamiliar, separadas o adosadas, ocupación de amplios espacios hasta lugares muy alejados del centro de las metrópolis y otros rasgos también semejantes.

Los bidonvilles, que estaban antes muy presentes en ambos países, han dejado de ser una caracte- rística significativa de dichas periferias, pero no han desaparecido. El problema en Francia viene de atrás, de la llegada de inmigrantes en los años 1950 y 60 para la reconstrucción del país con mano de obra abundante y barata procedente de Portugal, España y norte de África, lo que no siempre se resolvió con viviendas adecuadas, sino que dio lugar a la aparición de gran número de bidonvilles, principalmente en la periferia de Paris, aunque no solo en ella; Nanterre, llegó a tener 14.000 viviendas de este tipo a mediados de los años $60^{\circ}$. El intento de erradicarlos se hizo con un urbanismo de urgencia y de pésima calidad, con construcciones consideradas provisionales, pero que perdurarían durante años, y a veces hasta hoy.

Al mismo tiempo se planteaban también en las ciudades, como sucede hoy, problemas de paro, de los $\sin$ techo, de la pobreza. Basta con aludir al recuerdo del Abbé Pierre, o a la esforzada labor que, hasta el momento de su muerte en 1988, realizó el padre Joseph Wresinski, dedicando un gran número de artículos a ese problema, así como al de los bidonvilles, especialmente a través de la Revue Quart Monde, de nombre bien significativo. En lo que se refiere a la actualidad, no hay más que buscar en Internet "pauvreté en France" y otras similares para encontrar numerosas páginas con estadísticas y bibliografía oportuna sobre el tema.

Todavía es patente la turbación que a veces parecen tener los franceses ante los estudios que hablan de bidonvilles en los Treinta Gloriosos, y ante las noticias que señalan su existencia hoy día y de las actuaciones urbanísticas que se emprenden para su erradicación. Es significativo en este sentido el eco que está teniendo el ensayo del geógrafo Philippe Vasset sobre la cincuentena de es-

8 Diversas referencias a Italia, Francia y España en Tatjer Mir 2010 en publicación. De manera general, puede verse también Gastaut 2004. y sobre la evolución más reciente Brissuel 2002, Damon, s.f. 
pacios en blanco que ha identificado en el mapa 1:25.000 de la región Ile-de-France, mapa 2314 OT del Institut Géographique Nationale, la cartografía oficial de la periferia de las ciudades francesas. Causa extrañeza que, como él mismo escribe tras su exploración del mundo que escapa a la cartografía:

"au bout de deux mois, j'avais complètement abandonné l'idée de faire apparaître la moindre parcelle de merveilleux; les blancs des cartes masquaient, c'était claire, non pas l'étrange, mais I'honteux, l'inacceptable (...) Sur des centaines de kilomètres, ce sont des maisons à demi construites et déjà abandonnées, des bandes d'exclusion le long des frontières, des zones franches, des villesentrepôts, des galeries commerciales et ces dalles de béton ceintes de hauts grillages où les zones de jeu peintes sur le sol sont depuis longtemps effacées... En lieu et place des mystères espérées, je ne trouvait qu'une misère odieuse et anachronique, un bidonville caché aux portes de Paris" (Vasse, 2007).

También sorprende que, como en España, se intenten hoy erradicar áreas de barracas. La prensa e Internet informan ampliamente sobre el problema: en 2005 se hablaba de la difícil rehabilitación de las viviendas precarias construida para los inmigrantes magrebinos en los años 1950 a 1970, y de los "oubliés de Cassis", uno de los últimos bidonvilles de Francia; en 2006 eran las noticias sobre graves problemas de escolarización en el bidonville de Villeurbane, en la aglomeración de Lyon, habitado por búlgaros y rumanos y con una orden de destrucción; en enero de 2007, fueron las noticias del bidonville de Bobigny, en lle-deFrance, que se había levantado en pocos meses, y que fue arrasado con bulldozers, a la vez que se proponía la construcción de viviendas de urgencia social; en junio de 2008 se conocieron los problemas del bidonville y sector de autocaravanas de Rousseau Mirabeau en Marseille, con su población de gitanos, que tuvieron gran eco en la prensa francesa; y en septiembre del mismo año la prensa informó ampliamente sobre la destrucción del bidonville de Saint-Ouen, donde vivían 600 gitanos rumanos, una parte de los cuales fueron repatriados a la fuerza a su país, como "retour humanitaire". La búsqueda en la prensa, o en Internet proporciona otras noticias sobre bidonvilles en Bouches-du-Rhône, Val-de-Marne, en la periferia de diversas ciudades francesas, especialmente en torno a Paris.

Las políticas de vivienda fueron asimismo muy parecidas en España y Francia a otras que se aplicaban en países europeos democráticos. También los problemas de los grands ensambles, y es cierto que los agentes urbanos y los promotores en particular influyeron en las periferias de las grandes ciudades ${ }^{9}$. Los problemas en España y en Francia fueron en ocasiones similares: el diseño poco cuidadoso, los equipamientos insuficientes, la mala construcción de los edificios que ha obligado a destruir algunos (por ejemplo Les Coquettes, en Lyon) ${ }^{10}$, o de renovarlos con inversión pública, el alejamiento en la periferia, la segregación, el descuido de los espacios públicos y comunitarios, los problemas sociales, las drogas... Luego la revuelta de los banlieusards, que ha sido mayor en Francia que en España, aunque podemos temer que pueden ser igualmente semejantes en un próximo futuro.

La ciudad mundial global está hoy hiperconectada y es cada vez más parecida en sus edificios, actividades y formas de vida y de cultura (o de multicultura). $Y$ también, al mismo tiempo, es similar la ciudad internamente fragmentada, que reúne todas las contradicciones y todas las diferencias sociales y económicas que se dan en el mundo. Ya Raymond Ledrut y otros sociólogos franceses ha-

9 Puede verse sobre ello la comunicación de Pollard en este mismo Coloquio; y Pollard, p. 11

10 En algún momento se habló de la necesidad de destruir en Francia un total de 20.000 viviendas de grands ensembles en el año 2000 y 150.000 en los años siguientes, debido a la degradación por defectos técnicos en la construcción, Capel 2002, p. 430. 
bían señalado la presencia del mundo rural en la ciudad; todas las megalópolis, incluso las francesas como París, coinciden en los márgenes y en las zonas de suelo rural periférico en vías de transformación. También en París y en las ciudades francesas se producen, como reflejan ciertas cifras, situaciones de exclusión. Los problemas de la inmigración son sorprendentemente similares: los que no puede llegar, los detenidos por las fronteras de Schengen, los que arriban y son confinados en campos de internamiento, los que consiguen entrar y pueden vivir, porque tienen papeles, pero no tienen trabajo, los clandestinos y los sin papeles, los que llegan y viven, pero lo hacen en una periferia mal equipada y sin esperanzas, y que producen periódicamente incendios de desesperación, los que viven y están integrados pero se ven excluidos del bienestar por razones económicas, o sus viviendas en peligro porque no pueden pagar las hipotecas, los que viven y tienen trabajo pero están amenazados por los cambios posibles en las leyes de inmigración, los viejos, los sin techo, los excluidos del sistema por la educación insuficiente, condenados a empleos marginales, inestables y mal pagados, los hijos de inmigrantes que son franceses y viven en la periferia y se sienten periféricos ignorados o injusta y a veces brutalmente tratados, los marginados por la drogadicción. Luego están los que queman automóviles y escuelas en la periferia para ser visibles y expresar su rabia, los que adoptan valores contraculturales o al margen de la cultura oficial dominantes y se reflejan en el rap, en la droga y en otros hábitos que intentan ser singulares e identificadores.

Los estudios que algunos científicos sociales españoles hicieron en Paris durante los años 1960 permitieron conocer los procesos de renovación urbana en las áreas centrales de las ciudades francesas y el inicio de lo que luego se calificaría en Gran Bretaña como gentrificación. Los trabajos de Manuel Castells sobre la renovación del centro de Paris (Castells, 1972, entre otros) posibilitaron tomar conciencia de cambios que también se producían en las grandes ciudades españolas, y que se estudiarían luego ampliamente en este país.

Por otra parte, gracias a algunos autores franceses con los que teníamos relaciones a fines de los años 1960 y comienzos de los 70 podíamos pensar en procesos que se desarrollaban con gran fuerza en Francia y empezaban también en España al final de la década de desarrollo de los 60 . Los estudios que Jean-Pierre Garnier dedicó en Francia al papel de la planificación urbana en el neocapitalismo (Garnier, 1976), eran más o menos contemporáneos de los que arquitectos y científicos sociales españoles (por ejemplo el Laboratorio de Urbanismo de Barcelona, muy abierto a todo lo que se hacía en otros países) realizaban sobre el papel de la planificación en la gestión de las contradicciones, y a los primeros estudios sobre el papel de los agentes urbanos en la producción de la ciudad.

En los años 1970 era posible comparar los agentes urbanos y las estrategias que seguían para la producción del espacio urbano, en Francia y en España. De manera similar, tuvimos conciencia de lo que significaba la comedia urbana, y la presencia "des barbares dans la cité", es decir el paso "de la tyrannie du marché à la violence urbaine", por utilizar el título del libro de Jean Pierre Garnier publicado en 1996. Más recientemente otros libros de este mismo autor, como el titulado Une violence éminenment contemporaine (2010) permite conocer las resistencias que existen para identificar la naturaleza de los conflictos que oponen a los ciudadanos ordinarios con aquellos para quienes el espacio urbano es una fuente de beneficio.

También tuvimos conciencia de que los problemas de la participación eran similares en Francia y en España. Christian Beringuier nos ilustró en el Coloquio sobre L'Analyse interdisciplinaire de la croisance urbaine (1971) sobre las estratagemas 
que se realizaban en muchos municipios para que la fase de alegaciones no tuviera la necesaria publicidad (por ejemplo colocar el anuncio en un lugar poco visible y fijar el plazo en el mes de agosto) (Beringuier, 1972), de manera similar a lo que sucedía también en España.

La política de creación de parques naturales o de zonas naturales y paisajísticas protegidas y la utilización de las mismas para un negocio inmobiliario en sus márgenes (semiprivatizando a veces en cierta manera el disfrute de esos espacios protegidos) es algo digno de estudiar tanto en Francia como en España, y en ambos países existen ya trabajos que pueden dar lugar a dicha comparación.

No querría pensar que a los científicos sociales franceses les es más fácil echar una mirada crítica sobre otros países que sobre el suyo propio. Pero es lo que, en ocasiones, uno está tentado de concluir a partir de su actitud en el estudio de otras realidades y su mirada hacia el interior.

Pero más allá de estos desahogos, que tratan de estimular comparaciones más cuidadosas en el futuro, debemos ahora mirar hacia las aportaciones que se han realizado en este encuentro. El Coloquio se ha estructurado en varias secciones, dedicadas sucesivamente a la evolución del marco legal, a los movimientos vecinales y la actuación de los agentes urbanos, a la expansión periférica, a la vivienda, a la renovación urbana; y ha finalizado con un cuestionamiento del modelo de desarrollo urbano y económico español. En esta conclusión voy a limitarme a algunas reflexiones a partir de determinadas ideas que se han presentado y debatido en varias secciones.

\section{Marco legal estatal y regional. EI cambio en las reglas del juego en el urbanismo}

\section{La legislación urbanística española}

Creo que de entrada ha de valorarse muy positi- vamente la evolución española desde la transición política a la democracia. Tenemos una Constitución que es seguramente una de las más avanzadas de Europa, y que fue elaborada por consenso entre todas las fuerzas políticas. Su artículo 47 establece de forma taxativa que "todos los españoles tienen derecho a disfrutar de una vivienda digna y adecuada. Los poderes públicos promoverán las condiciones necesarias y establecerán las normas pertinentes para hacer efectivo este derecho, regulando la utilización del suelo de acuerdo con el interés general para impedir la especulación"; y añade que "la comunidad participará en las plusvalías que genere la acción urbanística de los entes públicos".

España pasó de un régimen centralista a uno descentralizado, uno de los más descentralizados de Europa, tanto desde el punto de vista objetivo (del derecho comparado) como subjetivo y social (del sentimiento de descentralización que tienen los habitantes de las diferentes Comunidades Autónomas). No existe algo igual en Francia.

En el actual marco institucional español están claramente señalados el nivel estatal, el de las Comunidades Autónomas (que podemos llamar subestatal) y el de los municipios, o nivel local. Hay también, lo que no siempre ocurre en otros países, posibilidades de asociaciones supramunicipales, y de planes territoriales.

Pero, sin duda, la aplicación práctica de los principios generales y el ejercicio de la función pública se ha visto afectada por la complejidad de las situaciones políticas realmente existentes, por las expectativas desmesuradas de una parte de la ciudadanía, por la insuficiente capacidad de gestión, por la falta de eficacia, por los cambios legislativos (de las leyes y de sus reglamentos), por los desacuerdos entre las distintas instancias y, eventualmente, por la corrupción.

En algunas de las comunicaciones presentadas a este Coloquio se han señalado las líneas esencia- 
les de la evolución del sistema legal urbanístico español ${ }^{11}$. En relación con la evolución de dicho marco legal, podemos hacer varias consideraciones generales, que tienen algunas implicaciones.

\section{Régimen político y normas urbanísticas}

Un punto que me parece importante destacar es que un régimen autoritario o dictatorial puede hacer una buena legislación urbana, contribuyendo a avanzar en el control público del urbanismo. El caso de la Dictadura de Primo de Rivera, con la promulgación del Estatuto Municipal de 1924, es bien significativo. A él podemos añadir el del franquismo y la aprobación de la Ley del Régimen del Suelo y Ordenación Urbana de 12 de mayo de 1956.

Vista en perspectiva, no cabe duda de que la Ley del Suelo de 1956 fue una buena ley para el urbanismo. Luciano Parejo la ha calificado como "cuerpo extraño en la obra legislativa de este periodo de la Dictadura de Franco". Una legislación que, en todo caso, supuso un paso decisivo en la consideración del urbanismo como función pública, y que era resultado de una compleja evolución en el campo del derecho español ${ }^{12}$. La perspectiva determinante pasa a ser el interés general (expresado o definido por el poder público), y el aprovechamiento urbanístico (edificabilidad y uso del suelo y su intensidad). Otro asunto es que la Ley se cumpliera, y son muchos los ejemplos que se han señalado de incumplimiento, facilitado por la

11 Especialmente significativas son en este sentido las excelentes presentaciones de Luciano Parejo y Antonio Montiel.

12

2 Bassols 1973 y 2006; en este último trabajo el autor realiza el análisis desde la perspectiva de la ciencia de la legislación y de la sociología jurídica, y señala la trascendencia que tuvo en su elaboración la Ley de Solares de 1945, y la legislación sobre grandes ciudades españolas de 1944 a 953, así como el impulso de la creación en 1949 de la Jefatura Nacional de Urbanismo, adscrita a la Dirección General de Arquitectura del Ministerio de la Gobernación. Fue fundamental el papel del arquitecto Pedro Bidagor Lasarte (1906-1996), que elaboró el Plan General de Ordenación Urbana de Madrid, y dirigió la Oficina técnica de la Junta de Reconstrucción de Madrid (1939-1946). falta de controles políticos democráticos ${ }^{13}$.

La legislación española ha atribuido tradicionalmente un papel importante a los propietarios del suelo en la promoción y en la gestión urbanística. Así lo hacían en el siglo XIX las leyes de Ensanche. La Ley del Suelo de 1956 al asignar la calificación de urbanizable a una parte del término municipal concedía automáticamente unas plusvalías enormes a los propietarios que tenían sus tierras en el sector calificado, pero perjudicaba a los restantes. La decisión del poder público se situaba por encima de la posibilidad de disponer que, como propietario tenía el titular del suelo, lo que introducía, de alguna forma, una limitación al derecho de propiedad.

La administración recibía, además, la posibilidad de intervenir, expropiar o ejercer las facultades de tanteo y retracto para el aprovechamiento del suelo. Lamentablemente, por un lado, no disponía de recursos suficientes para hacerlo y, por otro, podía no ejercer dichas facultades, por razones justificadas o por la capacidad de influencia política que tenían los propietarios del suelo en diversas instancias, desde la estatal a la municipal.

En la Ley del Suelo de 1956 el Plan General pasó a tener una posición central. Señalaba los objetivos, se convertía en un instrumento para la ordenación del territorio municipal, y explicitaba el modelo de ciudad que se pretendía alcanzar, así como la forma como había de ordenarse, asignando las modalidades de utilización del suelo. La calificación del suelo en urbano, urbanizable y no urbanizable constituye un aspecto fundamental de esta Ley, así como las atribuciones que se conceden a los municipios para elaborar sus planes generales de ordenación urbana, obligatorios a partir de cierto umbral de población.

A pesar de esa legislación, los municipios pudieron tardar en elaborar sus planes generales. Pero

${ }^{13}$ Yo mismo señalé algunos en el libro Capitalismo y morfología urbana en España, 1975. 
aun así, en 1974 existían ya 1.116 Planes de Ordenación Urbana, entre los cuales se encontraban los de 382 municipios de más de 10.000 habitantes, es decir casi todas las áreas urbanas españolas (Capel, 1975, p. 88-89).

Por otra parte, el problema fundamental fue, como he dicho, que la norma legal no se aplicó siempre de forma estricta. La misma administración pública podía no cumplirlo, al situar equipamientos fuera de la normativa. $Y$ los agentes privados (especialmente propietarios del suelo y promotores) tuvieron muchas oportunidades para actuar también al margen de la normativa. Por ejemplo, en el caso de los propietarios cuyo suelo era calificado como no urbanizable y que parcelaban suelo rústico y lo vendían para autoconstrucción ${ }^{14}$.

Luciano Parejo estima que la Ley "no llegó a tener plena efectividad", debido especialmente "a que su compleja trabazón de técnicas no estaba al alcance de la capacidad administrativa y de gestión de la mayor parte de la Administración local española". También alude al "inmediato desarbolamiento de la específica organización administrativa diseñada en la Ley al servicio de su ejecución, con adopción de medidas legislativas contradictorias con su filosofía". En los años finales del franquismo existían ya suficientes estudios que mostraron con claridad todo eso ${ }^{15}$, y que se intensificaron con la transición política.

La Ley de 1956 experimentó una primera adaptación a las nuevas circunstancias económicas y políticas en 1975, con un texto único refundido por Real decreto el 9 de abril de 1976. Un aspecto importante de dicha reforma -realizada en el contexto de una crisis económica que había acabado con la fase de desarrollo económico y urbano de la dé-

\footnotetext{
14 Pueden consultarse en este sentido los trabajos del Laboratorio de Urbanismo de Barcelona, entre los cuales los de Joan Busquets que dedicó al tema su Tesis doctoral (Las coreas de Barcelona, 1974), y ha resumido algunas de sus ideas en Busquets 1975 y 2004.

15 Algunos de los cuales fueron citados en el libro Capitalismo y morfología urbana en España (1975).
}

cada anterior-, era la posibilidad de flexibilizar el planeamiento o incluso de urbanizar en el marco de la programación de las actuaciones, así como el urbanismo concertado con la iniciativa privada. A partir de 1975 se inicia el proceso de transición política. Puede afirmarse que la democracia por sí sola no asegura un buen sistema legal de control del urbanismo. Depende de cómo se legisle, y esto a su vez del partido que tiene la mayoría en el Parlamento o Congreso de los Diputados. El caso de la legislación urbanística producida en España durante el gobierno del Partido Popular, y en concreto la Ley de 1998, es significativo en este sentido.

A partir de la transición política, con la aprobación de la Constitución española de 1978 se hizo necesario un nuevo marco legal urbanístico. El artículo 47 establecía, como hemos visto, limitaciones a la propiedad privada. Al mismo tiempo, se señalaba la exigencia de gestionar de forma adecuada los recursos naturales (art. 45) y la necesidad de conservar el patrimonio histórico, artístico y cultural (artículo 46).

Desde los años 1950 las ciudades habían crecido intensamente y los problemas urbanos habían superado ampliamente el marco municipal, que era el esencial en la Ley de 1956. El texto refundido de la Ley de 1975, en 1976, había representado ya un paso importante para superar dicho ámbito, ante la necesidad de coordinar el desarrollo urbano en diferentes municipios contiguos, potenciando la planificación supramunicipal. Se preveía para ello la puesta en marcha de Planes Directores Territoriales de Coordinación (artículo 3 y 5). Los citados planes podían tener ámbito supraprovincial, provincial o comarcal ${ }^{16}$.

El mecanismo para realización de dichos planes no se vio luego desarrollado en normas posteriores, por lo que tuvieron escasa efectividad. Pero suponían un paso significativo en la dirección del

\footnotetext{
${ }^{16}$ Titulo I, cap. $1, \operatorname{art}^{\circ} 6$ y 8.
} 
planeamiento supramunicipal en todos los casos en que fuera necesario, y no solo en el de las áreas metropolitanas. Lo que abría el camino hacia la planificación territorial calificada como ordenación del territorio -versión del aménagement francés y de otras figuras legales de países europeos.

Por otra parte, la creación del Estado de las Autonomías y la transferencia de muchas competencias a las Comunidades Autónomas suponía nuevas exigencias legales, que se fueron concretando en los Estatutos de Autonomía que se aprobaron a partir de 1979 (fecha del Estatuto de Autonomía del País Vasco). En ellos se han ido asumiendo las competencias de urbanismo, dejando al Estado la facultad de legislar para establecer el marco general.

En esta situación el Estado aprobó la Ley 8 de 25 de julio de 1992, y el texto refundido aprobado por Real Decreto Legislativo 1/1992, de 26 de junio. Dicho decreto recordaba que la disposición final segunda de la Ley 8/1990, de 25 de julio (sobre Reforma del Régimen Urbanístico y Valoraciones del Suelo), había "autorizado al Gobierno para que en el plazo de un año desde su publicación aprobara un Texto Refundido de las disposiciones estatales vigentes sobre suelo y ordenación urbana, comprendiendo también la regularización, aclaración y armonización de dichas disposiciones"; y aludía asimismo a las "dificultades objetivas que la tarea refundidora ha presentado se derivan de las profundas diferencias existentes entre la vigente Ley sobre Régimen del Suelo y Ordenación Urbana, de 9 de abril de 1976, y la citada Ley 8/1990, además de la amplitud de la delegación legislativa encomendada, así como de los diversos Reales Decretos-leyes que sobre la materia se han dictado".

Todavía añadía que esas dificultades se veían acrecentadas por "las innovaciones que en materia urbanística ha introducido la Constitución, al atribuir a las Comunidades Autónomas competencias sobre ordenación del territorio, urbanismo y vivienda (artículo 148.1.3)" y al imponer limitaciones al derecho de propiedad para impedir la especulación y para afirmar el derecho la comunidad a participar en las plusvalías generadas por la acción urbanística de los poderes públicos. Todo ello había impedido cumplir los plazos establecidos para elaborar la citada refundición, que finalmente pudo promulgarse como Texto Refundido de la Ley sobre el Régimen del Suelo y Ordenación Urbana (aprobado, como hemos visto, en Consejo de Ministros el día 26 de junio de 1992).

En dicho texto refundido se planteó el problema del precio del suelo y su repercusión en el de las viviendas. El artículo 3.5.c estableció que "la competencia urbanística en lo que se refiere a la intervención en la regulación del mercado del suelo" confería a la administración pública la facultad de "constituir y gestionar patrimonios públicos de sueIo" ${ }^{17}$; y de forma general, en esta Ley se aseguraba la posibilidad de la expropiación de suelo por razones de interés general, de acuerdo con lo establecido en la Constitución.

El problema del precio del suelo dio lugar a amplios debates, ya que -en el contexto del ambiente político y económico neoliberal que había pasado a dominar en muchos países, e influía asimismo en la Unión Europea-, había también en España posiciones favorables a la liberalización del suelo. Poco después, la llegada al gobierno del Partido Popular en 1996 representó un cambio importante respecto a las políticas que había sostenido en ese sentido el Partido Socialista. El Real DecretoLey 5/1996 de 7 de junio, aprobaba medidas liberalizadoras en lo que se refiere al suelo, reafirmadas en la Ley 7/1997, de 14 de abril. Se apoyaba en la idea de que el encarecimiento del suelo era

\footnotetext{
17 Principio completado por otros artículos, como el 61 que permitía expropiar "para constituir y ampliar el Patrimonio Municipal de suelo y otros patrimonios públicos de suelo" o para construir viviendas sociales.
} 
resultado de la normativa urbanística, y que se abarataría si se declaraba urbanizable todo el suelo existente, excepto aquel que por sus valores naturales se declarara explícitamente protegido. La evolución posterior mostraría la falacia de estos argumentos y las consecuencias desastrosas que tendrían para el desarrollo urbano.

Un hecho de extraordinaria importancia en el desarrollo de la legislación urbanística española fue la Sentencia del Tribunal Constitucional de 20 de marzo de 1997, ante los recursos de varios parlamentos autonómicos que consideraban que la Ley sobre el Régimen del suelo y Ordenación Urbana de 1990 vulneraba sus competencias. La sentencia declaró inconstitucional la legislación estatal sobre urbanismo promulgada durante los años anteriores. La consecuencia inmediata fue la necesidad de que las Comunidades Autónomas legislaran en materia urbanística, sobre las que tenían competencias exclusivas, para hacer uso de dichas competencias, modificando la Ley de 1975, que había pasado a ser vigente y era preconstitucional. Algunas Comunidades se limitaron a adoptar la Ley estatal de 1990, y otras realizaron una primera legislación urgente sobre la materia, que se intensificaría y perfeccionaría en años sucesivos. Todas las Comunidades Autónomas españolas poseen en estos momentos normativas legales propias en materia de urbanismo, aunque el sentido de dicha legislación se ha visto afectado por la composición política de los parlamentos autonómicos.

Por parte del Estado, la Ley 6/98 de Régimen del Suelo y Valoraciones constituyó un esfuerzo para adaptar la legislación estatal a la Sentencia del Tribunal Constitucional. Dicha legislación, promulgada por el gobierno del Partido Popular, aceptaba la liberalización del suelo, con la posibilidad de una urbanización general del territorio por iniciativa y actuación de los agentes privados.

En el preámbulo de la Ley se afirmaba que era necesaria "una mayor flexibilidad que, de un lado, elimine los factores de rigidez que se han ido acumulando y, de otro, asegure a las Administraciones públicas responsables de la política urbanística una mayor capacidad de adaptación a una coyuntura económica cambiante, en la que los ciclos de expansión y recesión se suceden con extraordinaria rapidez". Y se reafirmaba el papel subsidiario del Estado, recordando que "el legislador estatal, que carece constitucionalmente de competencias en materia de urbanismo y de ordenación del territorio en sentido propio, no puede por sí solo afrontar la tarea indicada, a la que sólo puede aportar una solución parcial”.

En esos años, el crecimiento económico y el incremento de la población provocaron un aumento de la demanda y, en seguida, de la oferta de vivienda por la iniciativa privada. Se llegaron a construir más viviendas que en otros países europeos. Una urbanización excesiva, insostenible, poco atenta al medio natural, como han puesto de manifiesto en España numerosos autores, entre los cuales uno de los presentes en este Coloquio, José Manuel Naredo. La planificación, fue cuestionada en las normas legales, y con ella la función pública en el urbanismo. Al mismo tiempo, se magnificaron los principios del mercado, de la iniciativa privada y se permitió la extensión de la urbanización a todo el territorio, excepto en los casos en que estuviera explícitamente protegido; pero incluso en esos casos se pudo vulnerar la protección, como muestra, entre otros, el caso del hotel del Algarrobico, junto a Carboneras, situado en una parcela no urbanizable del perímetro del Parque Natural de Cabo de Gata-Níjar. Todo lo cual contribuyó a producir un grave deterioro del urbanismo.

En 2004 llegó nuevamente al gobierno el Partido Socialista, y la legislación urbanística experimentó otra vez un cambio importante. La Ley 8/2007 de 28 de mayo y el Real Decreto Legislativo 2/2008, 
de 20 de Junio significaron un cambio en la política del suelo, dando mayores atribuciones a la administración pública.

Ante todo, se trataba de "evitar la dispersión de las normas y el fraccionamiento de las disposiciones que recogen la legislación estatal en la materia"; supone, por tanto, la reafirmación de la necesidad de un marco estatal claro al que debe adecuarse la legislación de las Comunidades Autónomas. Al mismo tiempo la Ley afirmó los principios de desarrollo territorial y urbano sostenible (artículo 2), con "el uso racional de los recursos naturales armonizando los requerimientos de la economía, el empleo, la cohesión social, la igualdad de trato y de oportunidades entre mujeres y hombres, la salud y la seguridad de las personas y la protección del medio ambiente, contribuyendo a la prevención y reducción de la contaminación"; también afirma que se trata de conseguir un medio urbano "en el que la ocupación del suelo sea eficiente, que esté suficientemente dotado por las infraestructuras y los servicios que le son propios y en el que los usos se combinen de forma funcional y se implanten efectivamente, cuando cumplan una función social"

Con la nueva Ley se producirá un cambio fundamental, al reconocer nuevamente la importancia decisiva de la actuación pública en la ordenación territorial y urbanística, y en particular se señala que la dirección y el control de los procesos urbanísticos debe recaer en los poderes públicos. También establece que la comunidad debe participar en las plusvalías urbanísticas generadas por la acción de los entes públicos, y reconoce la necesidad de participación de los ciudadanos (artículo 3.2), así como el derecho a la información de éstos, así como "la participación ciudadana en la ordenación y gestión urbanísticas". Finalmente, la Ley separa también "el régimen del derecho de propiedad del suelo y el de la promoción y ejecución de actuaciones urbanísticas" y establece un nuevo sistema objetivo de valoración del suelo.

En los años en que, bajo la legislación del Partido Popular, se producía el deterioro del urbanismo en España, en otros países europeos la situación tenía aspectos similares $\mathrm{y}$, al mismo tiempo, diferentes. El derecho comparado permite comprobar que en un mismo entorno sociopolítico internacional pueden existir diferencias significativas en la legislación urbanística, que se relaciona con tradiciones políticas e intelectuales propias, así como con las estructuras económicas y sociales.

España, integrada en la Unión Europea, debe atender las normas que se establecen para todo ese ámbito. La Estrategia Territorial Europea aprobada en la reunión de ministros celebrada en Postdam en 1999 (Mora y Pimenta, 1996-2003), y la que al año siguiente se celebró en Leipzig sobre el tema "Desarrollo urbano y cohesión territorial", supusieron avances en el esfuerzo para conseguir un espacio más cohesionado e integrado. Luciano Parejo ha hablado en este mismo Coloquio de que en esos años se produce una "progresiva separación del modelo español de ocupación y utilización del territorio del modelo continental europeo". En dichos documentos se ponía énfasis en la ciudad compacta, frente al urbanismo disperso, y en la necesidad de un urbanismo sostenible. Unapregunta pertinente es la de cómo ha sido posible que un país se salte esas normas, y cómo reaccionaron los otros estados.

La impresión que se tiene es que, frente a los objetivos comunes europeos, en España se ha favorecido la difusión de la urbanización, y se han permitido atentados al medio natural. Una urbanización salvaje que ha destruido paisajes naturales, área litorales y de montaña. Parece como si España fuera un Estado aparte en el funcionamiento de Europa.

Sin embargo, no estoy seguro de que haya sido algo exclusivo de España. Puede formularse la hipótesis de que en aquellos países europeos en los 
que no se ha producido ha sido por carencia de una demanda tan intensa. $Y$ que en aquellos en que dicha demanda ha existido, el urbanismo salvaje ha tenido igualmente lugar. El caso de Francia es, me parece, especialmente significativo.

En los últimos años hemos podido comprobar que para algunos franceses, con poca perspicacia, el desarrollo urbanístico español se veía como un modelo de muy positivas consecuencias para el crecimiento económico. Tal vez por ello, el urbanismo salvaje lo encontramos tanto en uno como en otro país. Las recientes inundaciones que han afectado a la costa atlántica francesa tras el paso del ciclón Xynthia a comienzos de marzo de 2010 han provocado daños considerables, y han llevado al presidente Sarkozy a criticar las viviendas construidas demasiado cerca del mar, el "urbanismo salvaje", que se ha producido en la costa al norte y sur de La Rochelle; en relación con ello, ha afirmado: "no podemos transigir con la seguridad, por eso debemos reflexionar sobre los planes urbanísticos para que esta catástrofe no vuelva a suce$\operatorname{der}^{18}$.

En cualquier caso, todo ello muestra que además de la legislación, hace falta voluntad política de aplicarla, y mecanismos eficaces para ello.

\section{Pensar el modelo urbano desde los problemas que existen}

El debate sobre el modelo de desarrollo puede tener -como ha tenido recientemente en Españavarias versiones, según las diferentes escalas que consideremos.

Puede hablarse, ante todo, de los modelos de desarrollo a escala mundial. Un debate suscitado desde los años 1960 cuando se planteó la cuestión de los límites del crecimiento, y agudizado más recientemente con el problema de la sostenibilidad. En los últimos años la crisis económica ha

18 El País 2 marzo 2010, p. 6; los puntos más afectados fueron L'Aiguillon sur mer, Faute sur Mer, La Rochelle, Plage de Aytré. vuelto a poner en primer término, otra vez, el cuestionamiento de la economía capitalista.

En el caso de España, puede discutirse, además, el modelo de desarrollo económico y urbanístico que se ha seguido. Un modelo que ha pasado por diferentes fases de valoración. A comienzos de los años 2000 causaba admiración no solo dentro, sino también fuera. En España parecía que habíamos llegado al grupo de países más desarrollados, existía superávit en los presupuestos del Estado, las cuentas cuadraban más que en Alemania, se admitía al país en el G-20 y aumentaba el nivel de equipamientos, la calidad de vida y la autosatisfacción.

Ese modelo y los niveles alcanzados se veían con admiración también en Francia. El desarrollo turístico era envidiado por algunas regiones francesas, italianas y de países iberoamericanos, como México o Brasil. Las consecuencias de los flujos turísticos para las áreas receptoras eran siempre valoradas positivamente. Nadie parecía notar las consecuencias negativas que tiene la congestión, la subida de precios, y otras consecuencias que se perciben en los lugares más turísticos como París, Venecia o Barcelona.

En todo caso, nadie cuestionaba, y todavía no se hace de forma clara, el mismo movimiento turístico, la obsesión por los viajes, por tener residencias secundarias en países con atractivos naturales, culturales y sociales, el deseo de ir a cuidarse en países con buenos niveles de confort y medicación.

Hay, además, otro tercer nivel de debate, el de los modelos de desarrollo urbano o metropolitano. En este sentido la discusión sobre el modelo Barcelona ha sido especialmente significativa, y ha puesto en cuestión algunas políticas seguidas en esta ciudad.

En el caso de Barcelona el éxito de las transformaciones que se produjeron en los años 1990, y de los Juegos Olímpicos, dio lugar a una explícita 
exaltación del "modelo Barcelona", que se pudo vender de forma amplia, especialmente en países iberoamericanos. Las críticas a ese llamado modelo Barcelona se dejaron sentir más tarde y se han incrementado en la última década ${ }^{19}$. En lo que se refiere a otro modelo de desarrollo, el de Madrid, José Manuel Naredo ha dado suficientes para que podamos juzgar sobre sus costes y consecuencias, así como sobre los beneficios que ha supuesto para algunos.

Los problemas del crecimiento del sector inmobiliario y de la crisis son ya conocidos. Una y otra vez se alude a razones que tienen que ver con la especulación y con la escasez de recursos de los municipios. Las descripciones y los diagnósticos son ya numerosos, claros y convincentes. Las comunicaciones que se han presentado en este mismo coloquio inciden nuevamente en ello.

Muchos lo veían venir y lo advirtieron. Pero no se hizo caso. Debemos analizar porqué se obsesionaban los ayuntamientos con la recalificación y la construcción, por qué se endeudaron las familias adquiriendo automóviles mayores, o comprometiéndose en la compra de la segunda vivienda, porqué se construían tantos campos de golf, porqué se optaba por el desarrollo postindustrial y se aceptaba como inevitable la clausura de industrias y talleres de larga tradición.

Las respuestas eran de tipo diverso, pero coincidentes en la necesidad de seguir esa vía de desarrollo. En la confrontación interna entre las regiones españolas, algunos cuestionaban: si en otras regiones se había hecho antes, porqué ahora no podían hacerlo ellos (como preguntaban los propietarios y promotores en las comarcas del litoral almeriense o murciano). Muchos, y especialmente los que se beneficiaban de ello, insistían en que no había alternativas económicas reales al turismo

19 He hablado en otro lugar del llamado Modelo Barcelona (Capel, 2005 y 2007), y Jordi Borja ha aludido a ello también en un excelente libro (Borja, 2010) y en una comunicación a este Coloquio. y la construcción, debido a la globalización de la economía, la competencia de países emergentes como China, y la intensificación de las deslocalizaciones industriales.

En ese contexto estalló la crisis, generada por los mecanismos especulativos que se pusieron en práctica, y que se relacionan con la abundancia de dinero líquido, la ingeniería financiera y las facilidades para la fluidez de los capitales. Se compran bienes porque se espera su revalorización, y así funciona el mercado de futuros en agricultura o materias primas. No debería extrañarnos que suceda también con el suelo y con la vivienda. Si lo hacen los financieros, no se ve bien por qué no iban a pensar en utilizarlo igualmente los ciudadanos corrientes, para asegurar sus ahorros.

A todo ello se une que no parece existir un proyecto de ciudad ni de organización del territorio. Es algo que se ha señalado varias veces en las comunicaciones presentadas al Coloquio. En una de ellas se afirma tajantemente: "la mayoría de las ciudades y de los territorios siguen sin proyectos de ciudad y de territorio en el nuevo milenio". Naturalmente, no son las ciudades, sino los políticos y técnicos que las dirigen. Pero debemos preguntarnos qué hay detrás de ello, y qué alternativas existían.

Hay seguramente un problema más general, la confusión sobre la política económica adecuada en una fase que algunos autores, y con referencia a determinados contextos, calificaron como postindustrial y postfordista. Tal vez los científicos sociales han tenido una influencia excesiva, y no siempre positiva, en los técnicos y los políticos, que aceptaron de manera apresurada estas ideas. No es la primera vez que sucede. Deberíamos examinar críticamente las consecuencias negativas que la aceptación de las tesis sobre el subdesarrollo pudieron tener en algunos países, desde el punto de vista de las políticas económicas o, lo que es más importante, de las políticas simple- 
mente. O la aceptación de las ideas de centro y periferia, o de norte y sur, con consecuencias que, seguramente, han podido ser también negativas.

En realidad el problema fundamental es que los políticos o bien tienen una ideas que llevan a las consecuencias económicas urbanas que hemos conocido (en el caso de los políticos de derechas con su aceptación de las ideas económicas neoliberales), o bien dudan sobre las políticas a seguir (los políticos de izquierda y la izquierda en general). Estos últimos, en lugar de hablar de las alternativas económicas, de la necesidad de contener el consumo y evitar el despilfarro, del aumento de impuestos para construir equipamientos y asegurar los servicios sociales, de la formación de la juventud para el trabajo, de la difusión de ideales de esfuerzo y de compromiso social, parecen haber aceptado ideas que van en sentido contrario.

Lo que hay que hacer es profundizar en las causas reales de esa locura colectiva, de los políticos que la permitieron, de los profesionales y científicos sociales que no la percibieron y diagnosticaron cuando se estaba a tiempo (por ejemplo, el silencio estruendoso de los Colegios de Arquitectura y de las Escuelas Técnicas ante la especulación y corrupción inmobiliaria), de la complicidad de los ciudadanos con la especulación y los beneficios fáciles y rápidos, en esa lucha para no quedar el último en la obtención de ganancias que veían obtener a otros. $Y$ también de la confusión de los ayuntamientos sobre las posibilidades y las vías de desarrollo económico de sus localidades.

\section{Recursos municipales}

La falta de recursos municipales es un problema grave. Los Ayuntamientos fueron en el siglo XIX el último escalón de la administración del Estado. Se les atribuyeron servicios diversos (entre ellos la policía local y la educación) aunque escasos recursos económicos para ello

La insuficiencia crónica de recursos financieros de los municipios fue grande. A partir de 1925, la creación del Banco de Crédito Local les permitió acceder al crédito para servicios públicos. Pero la debilidad financiera fue constante. Los grandes ayuntamientos frecuentemente no podían pagar ni siquiera el gasto del alumbrado por gas o eléctrico. Fue un problema a lo largo del XIX intentar atender a una gran cantidad de servicios públicos nuevos (agua, desagüe, gas...) sin recursos para ello. Por eso, dichos servicios con frecuencia se privatizaron, aunque los Ayuntamientos pretendían controlarlos y asegurarlos, considerando que les correspondían a la administración municipal.

El Estado liberal tuvo en el siglo XIX una gran desconfianza ante el poder local. A veces justificada, por la influencia inmediata que tienen en él los caciques locales y la dificultad para luchar contra ella. Por esa razón se introdujeron numerosos controles a través de figuras como los secretarios de ayuntamientos o los interventores (Toscas 2008, Toscas y Ayala, 2003). Los recursos se les atribuían desde el Estado, como redistribución del presupuesto nacional.

El crecimiento de las ciudades durante el siglo $\mathrm{XX}$, a veces coincidiendo con situaciones de crecimiento económico débil, convirtió la situación en explosiva. En los años 1970 la población emprendió intensas acciones de reivindicación de servicios y equipamientos públicos, en una fase de crecimiento rápido de las necesidades urbanísticas (asfaltado de calles, agua y desagüe, basuras, tratamiento de residuos, transportes urbanos...) y de servicios (zonas verdes, polideportivos, bibliotecas...). A ellos se unían otras necesidades en sanidad, promoción económica, etc. Las reivindicaciones de la población se dirigieron, ante todo, al poder más inmediato, es decir, al poder local de los ayuntamientos, que seguían sin tener recursos para construir y mantener todos esos servicios.

Tras la Constitución de 1978 y los Estatutos de Autonomía, el Estado transfirió recursos a las Comunidades Autónomas, pero éstas no lo hicie- 
ron a los Ayuntamientos. Las Comunidades Autónomas gastan hoy entre un 35 y un 37 por ciento del gasto público, mientras que el de los ayuntamientos se ha mantenido en torno al 13-15 por ciento durante los últimos treinta años (Montiel, 2010).

Los ayuntamientos no tienen recursos financieros suficientes para atender a todas las funciones que han de desarrollar, y que están establecidas claramente en el artículo 142 de la Constitución, el cual establece que:

"las Haciendas locales deberán disponer de los medios suficientes para el desempeño de las funciones que la Ley atribuye a las Corporaciones respectivas y se nutrirán fundamentalmente de tributos propios y de participación en los del Estado y de las Comunidades Autónomas".

Hay que recordar, además, que el número de municipios en España es muy elevado, y que se han reducido poco en los últimos cincuenta años: han pasado de 9.200 en 1960 a 8.114 en 2010. Muchos de esos municipios son muy pequeños (en población y en superficie) y la inmensa mayoría no tiene personal técnico especializado. Debe advertirse que la cifra de municipios españoles que tienen menos de 100 habitantes es de 981, la de 100 a 200 asciende a 1.189 , de 200 a 500 existen unos 1659 y de 500 a 1.000 la cifra se sitúa en 1,122; en total, pues, unos 5.000 municipios cuentan con menos de 1.000 habitantes. Es evidente que difícilmente pueden asegurar los servicios técnicos necesarios para el control de su territorio, especialmente cuando los promotores privados les ofrecen compensaciones en forma de equipamientos o de otro tipo, y cuando muchos de ellos creen tener en el urbanismo y en la edificación la única posibilidad de desarrollo que se puede imaginar. Téngase en cuenta que la mayoría de esos pequeños municipios son rurales, y están seriamente preocupados por conseguir el crecimiento económico de sus territorios y el bienestar de sus habitantes, en una situación de rápidos cambios en la producción agrícola.

En ese contexto, los ayuntamientos vieron frecuentemente con alegría la fase de desarrollo inmobiliario que podía llegar hasta sus mismos términos municipales. A pesar del mandato constitucional sobre la necesidad de que dispongan de recursos propios, son escasos los que pueden recaudar, entre los cuales debe destacarse la importancia que tiene en las haciendas municipales la recaudación procedente de transacciones inmobiliarias y de la actividad inmobiliaria en general. Por ello recibieron favorablemente la innovación que suponía la figura del Agente Urbanizador, introducida en la Ley 6/1994 de la comunidad Valenciana, y mirada luego con admiración en otros ámbitos, ya que parecía permitir la expansión urbana y -en relación con ello- el fomento de la riqueza del municipio, con escasas exigencias de financiación. Por esa razón se comprometieron en una carrera de comportamientos insensatos. Confiaban en que el mercado absorbería todos los espacios urbanizados (cuyo precio crecía a cada transacción, aumentando ficticiamente la riqueza general) y las viviendas producidas ${ }^{20}$. A lo que puede añadirse la corrupción y las posibilidades de beneficio individual de algunos políticos; lo que, a pesar de todo el ruido mediático existente, es muy posible que hayan sido comportamientos minoritarios.

Necesitamos tener sentido del matiz. Desde luego, el sistema económico dominante favorece o estimula ciertos comportamientos. Pero debemos pasar a análisis más concretos. Son gobiernos concretos, empresarios, técnicos y elites que se pueden identificar; así como ciudadanos que también se benefician, ignoran o callan. El inmobiliario en España ha sido un industria que produce una mercancía específica (por el hecho de que no se puede trasladar), y lo ha hecho con las leyes del capitalismo. Al igual que hacen otros empresarios. Lo

${ }^{20}$ A lo que ha hecho referencia en este Coloquio la excelente comunicación de Montiel, 2010 (ejemplos de declaraciones insensatas en 10); véase también Burriel de Orueta, 2009. 
que se construía en España eran viviendas para los españoles, pero también residencias secundarias para españoles y extranjeros, para el movimiento de turistas que buscan el sol y el ambiente del país. A veces son esos mismos turistas ya instalados desde años atrás los que han denunciado que otros turistas (o ciudadanos españoles de lugares próximos o lejanos) vinieran a situarse cerca de los espacios que ellos habían ya colonizado, y empezado a destruir desde hace años. Ha habido nuevas formas de ocupación y nuevas alianzas. En el marco de la Ley de 1956 había propietarios que podían parcelar suelo y lo vendían para edificar fuera de normativa, como autoconstrucción, y se podían producir invasiones de terreno privados o públicos para viviendas precarias. En la nueva situación creada con la figura del Agente urbanizador son otros los mecanismos y alianzas que se han puesto en marcha, con la connivencia, en ocasiones, de una parte de los propietarios del suelo.

Necesitamos además comparaciones internacionales. Debemos preguntarnos si el caso español que se ha estudiado en este coloquio, sirve también para entender lo que ha sucedido en otros países. Los españoles enloquecieron, pero no solo ellos. También los ingleses, los franceses, los alemanes y otros europeos, inversores en viviendas secundarias en España. Al igual que los norteamericanos, inversores en sus propias viviendas con hipotecas subprime. Así como los empresarios inmobiliarios de esos países, que construían en su propios territorio y en otros, o la industria de la construcción y las sociedades financieras, que compraban y vendían en España, en Londres y Paris, asociados a veces a pequeños promotores españoles o a propietarios del suelo. Un negocio inmobiliario europeo multinacional y de la mafia de países del Este de Europa o de otros lugares. Que se desarrolló sin que los países europeos tomaran medidas decisivas para controlar el blanqueo de dinero; solo recientemente se han empezado a firmar algunos modestos acuerdos para limitar el secreto bancario, ante el escándalo de lo que ha ido sucediendo.

En relación con ese desarrollo inmobiliario se han hecho múltiples ensayos -al igual que se hizo en el sector financiero, y en otros- de nuevos productos inmobiliarios, acabados y listos para el beneficio privado. Hoy pueden ensayarse, fabricarse o promoverse de forma masiva nuevos modelos de ciudad en la periferia. Los recursos técnicos y económicos disponibles lo permiten. Nunca ha habido tantos medios disponibles para construir ciudad como existen hoy.

Han cambiado las posibilidades y las escalas de actuación. Si hay capital, las posibilidades son infinitas. Si en Dubai pueden fabricarse en el desierto ciudades y pistas de esquí, y si en Barcelona se puede imaginar una Olimpiada de Invierno, con una parte de su desarrollo en la misma ciudad, en pistas de hielo artificial, es que cualquier proyecto resulta verdaderamente posible. Depende del dinero que se tenga, o que se espera tener, del márquetin urbano, de la avaricia de los especuladores, de la ingenuidad de los ahorradores.

Respecto al pasado, ha habido cambios importantes en la disponibilidad de capitales y en los mecanismos de financiación. Se había producido un indudable aumento de la riqueza. Había mucho dinero disponible, real y ficticio: dinero de los salarios, de los ahorros familiares, capitales de los bancos españoles y extranjeros, dinero de la mafia y del blanqueo de capitales. $Y$ a veces mucha ansiedad por invertirlo para evitar su rápida desvalorización (lo que explica episodios como el Foro Filatélico o el de Gescartera). También mucho dinero ficticio (de las ganancias de bolsa, de las inversiones en arte...). Y posibilidades de financiación nunca antes existentes, a veces con garantías ("solo se presta a los que tienen") pero también, otras, incluso sin ellas; esto último no deja de ser 
admirable, y tal vez detrás de las hipotecas basura puede haber también aspectos positivos y valiosos para explorar más adelante, con vistas a la producción de vivienda para grupos populares.

Hay también miedo del futuro en las clases medias y populares. Miedos reales que dieron lugar desde el siglo XIX a la puesta en marcha de seguros diversos para atender a las situaciones de enfermedad, de muerte, de incendios, de servicio militar; y miedos nuevos que se han difundido en las últimas décadas: a quedarse sin empleo, a las pensiones de jubilación insuficientes, a no poder pagar la hipoteca... Es normal que las clases medias y bajas se vean seducidas por los mismos modelos que utilizan los grupos privilegiados. Nunca los modelos se han difundido tan rápida y ampliamente como hoy, a través de la prensa, los libros, el cine, la TV, los viajes o Internet.

La aspiración a "todos propietarios" no debe descalificarse. No es necesariamente mala por el hecho de que esa idea haya sido promovida por la burguesía desde el siglo XIX, y adoptada en España por la Dictadura de Franco, con argumentos que tratan de asegurar la paz social ("mejor todos propietarios que todos proletarios", defendió el primer ministro franquista de la Vivienda, José Luis de Arrese).

En todo caso, no culpabilicemos el deseo de las familias medias y populares a ser propietarios de su casa propia; la única propiedad que van a tener en su vida para dejar a sus hijos, además del recuerdo de algunos viajes y momentos de cambio en la cotidianeidad de una vida de trabajo continuo y esforzado. Sea bienvenida la propiedad de la vivienda familiar, si es posible, y aseguremos que las clases populares puedan transmitirla. Propongamos vías nuevas a partir de lo que hay, sin culpabilizar a los pobres que han conseguido esa vivienda, con un esfuerzo denonado, y que quieren dejarlas en herencia a sus hijos y a sus nietos. $Y$ pensemos en otras propiedades, de suelo y de capital, que de forma totalmente injusta se transmiten desde hace generaciones a personas que no han hecho el menor esfuerzo para generarlas (Capel, 2010).

En lo que se refiere al futuro, da la impresión de que en los próximos años vamos a seguir integrados en un área de economía liberal de mercado, que acepta la propiedad privada y la libre empresa; y que no podemos impedir que la Mano Invisible del Mercado actúe en la economía. Pero al mismo tiempo, se tienen numerosos datos que muestran que esa Mano ha sido en muchos casos poco diestra, o torticera. Por esa razón debería completarse, como muchos defienden, con la Mano Visible de la Regulación, de la ordenación y el control riguroso por la administración pública.

El mundo ha cambiado y va a cambiar mucho más. Estamos viviendo en toda Europa por encima de nuestras posibilidades. Hay un despilfarro, de todo, incluso de espacio urbano. Hemos de ser más moderados. Eso exige unos marcos legislativos de control, exigentes y mucho más estrictos. También una legislación inspirada en principios éticos y en la solidaridad internacional, que asegure un sistema fiscal progresivo y que penalice el despilfarro.

\section{Referencias}

ANALYSE. L'Analyse interdisciplinnaire de la croiisance urbaine. Toulouse, 1971. Colloques Nationaux du Centre National de la Recherche Scientifique, $n^{\circ}$ 931. Paris: Éditions du CNRS, 1972. 387 p.

BARON-YELLES, Nacima. Quarante ans d"urbanisation touristique et résidentielle des côtes espagnoles: émergence, pérennité et ambiguïté d"un contre-modèle urbanistique. En COLOQUE 2010 (en publicación).

BASSOLS COMA, Martín. Génesis y evolución del derecho urbanístico español, 1812-1956. Madrid: Montecorvo, 1973. 638 p. 
BASSOLS COMA, Martín. Ante el cincuentenario de la ley del suelo y ordenación urbana de 1956: el proceso de su elaboración y aplicación. Revista de Derecho Urbanístico y Medio Ambiente, Madrid, Abril 2006, $\mathrm{n}^{0} 225$. $<$ http://vlex.com/vid/cincuentenario-ordenacionurbana-elaboracion380554\#freetrial\#ixzzOhWbCYLW8>

BERINGUIER, Christian. Plan d'urbanisme et pratique politique. En ANALYSE, 1972. Traducción al español en BERINGUIER y otros, 1974.

BERINGUIER, Christian, CASTELLS, Manuel, MINGASSON, Christian y REMY, Jean. Urbanismo y práctica política. Barcelona: Los Libros de la Frontera, 1974.

BERNECKER, Walter L. La investigación histórica del "tiempo presente" en Alemania. Cuadernos de Historia Contemporánea, 1998, n²0, p. 8398.

BISSUET, Bertrand. Les municipalités confrontées à la réapparition des bidonvilles. Le Monde, 2711-2002.

BORJA, Jordi. Luces y sombras del urbanismo de Barcelona. Barcelona: UOC, 2010. 304 p.

BORJA, Jordi. Luces y sombras del modelo urbano español: el caso de Barcelona. En COLOQUE 2010 (en publicación).

BURRIEL DE ORUETA, Eugenio L. La planificación territorial en la Comunidad Valenciana (1986-2009). Scripta Nova. Revista Electrónica de Geografía y Ciencias sociales, 2009, vol. XIII, $n^{\circ}$ 306. <http://www.ub.es/geocrit/sn/sn306.htm>

BUSQUETS, Joan. Las coreas de Barcelona. Tesis doctoral dirigida por el Dr. Manuel de SoláMorales, Escuela Técnica Superior de Arquitectura de Barcelona, 1974

BUSQUETS GRAU, Joan. La urbanización marginal en Barcelona. Barcelona: Laboratorio de Urbanismo, Escuela Técnica Superior de Arquitectura, 1975. 2 vols.
BUSQUETS, Joan. Barcelona. La construcción urbanística de una ciudad compacta. Barcelona: Ediciones del Serbal (Colección La Estrella Polar), 2004. $471 \mathrm{p}$.

CABRERIZO, Casilda y RODRÍGUEZ CHUMILLAS, Isabel. Del desarrollo del territorio a la urbanización territorial: el caso de Getafe. En COLOQUE 2010 (en publicación).

CANOSA ZAMORA, Elia, FRANCO ALONSO, Óscar, GARCÍA CARBALLO, Ángela y SÁEZ POMBO, Ester. El ocaso del modelo unifamiliar en la vivienda social. En COLOQUE 2010 (en publicación).

CAPEL, Horacio. Capitalismo y morfología urbana en España. Barcelona: Los Libros de la Frontera, 1975. 142 p. (2ª edición 1977; $3^{\mathrm{a}}$ edición 1981; $4^{\mathrm{a}}$ edición 1983; nueva edición ampliada, Barcelona: El Círculo de Lectores, 1990). Disponible en $<$ http://www.ub.es/geocrit/LibrosElec/CapelCapitalismo.htm>

CAPEL, Horacio. Las dificultades del análisis interdisciplinar del crecimiento urbano. Revista de Geografía, vol. V, 1971, p. 123-136.

CAPEL, Horacio. La morfología de las ciudades. Volumen I, Sociedad, cultura y paisaje urbano. Barcelona: Ediciones del Serbal, 2002. 544 p.

CAPEL, Horacio (Coord). Ciudades, arquitectura y espacio urbano. Almería: Fundación Cajamar (Serie "Mediterráneo Económico", n 3), 2003. $504 \mathrm{p}$.

$<$ http://www.instituto.cajamar.es/mediterraneo/i ndice3.htm>

CAPEL, Horacio. El futuro de las ciudades. Una propuesta de manifiesto. Biblio 3W. Revista Bibliográfica de Geografía y Ciencias Sociales, 2004, vol. IX, n 551.

<http://www.ub.es/geocrit/b3w-551.htm>.

CAPEL, Horacio. El modelo Barcelona: un examen crítico. Barcelona: Ed. Serbal, 2005. 117 p.

CAPEL, Horacio. El debate sobre la construcción de la ciudad y el llamado "Modelo Barcelona". 
Scripta Nova. Revista Electrónica de Geografía y Ciencias sociales, 2007, vol. XI, $\mathrm{n}^{0} 233$. <http://www.ub.es/geocrit/sn/sn-233.htm>.

CAPEL, Horacio. Las pequeñas ciudades en la urbanización generalizada y ante la crisis global. Investigaciones Geográficas, 2009, n 70, p. 732.< http://www.igeograf.unam.mx/iggweb/ publicaciones/boletin_editorial/boletin/bol70/bltn70artA.pdf>.

CAPEL, Horacio. Geografía en red a comienzos del Tercer Milenio. Por una ciencia solidaria y en colaboración. Scripta Nova. Revista Electrónica de Geografía y Ciencias Sociales, 2010, vol. XIV, n 313.

<http://www.ub.es/geocrit/sn/sn-313.htm>.

CAPEL. Horacio. Urbanización Generalizada, derecho a la ciudad y derecho para la ciudad. En XI Coloquio Internacional de Geocrítica, Buenos Aires 2010 (en publicación).

CASTELLS, Manuel. Planification urbaine et mouvements sociaux: le cas de la rénovation urbaine à Paris. In ANALYSE 1972. Versión española, Planificación urbana y movimientos sociales. El caso de la renovación urbana en París. En BERINGIER et al., 1974, p. 125-160.

COLLOQUE. Actes du Colloque Internationelle, L'Urbanisme, la démocratie et le marché : une expérience espagnole (1970-2010), Institut d'Urbanisme de Paris, Créteil, 15-16 de marzo 2010 (en publicación).

DAMON, Julien. Mal logement, bidonvilles et habitat indigne en France. Recherches et Prévisions, 2004, p. 116-119

$<$ http://www.feantsa.org/files/Month\%20Publicat ions/FR/Articles_et_documents_lies_au_Flash/ mal\%20logement $\% 20$ bidonvilles $\% 20$ en $\% 20$ fran ce.pdf>.

FERNÁNDEZ SALINAS, Víctor: La reforma interior de Sevilla entre 1940 y 1959. Sevilla: Universidad de Sevilla/Consejería de Obras Públicas y Transportes, 1992. 341 p.

GARNIER, Jean Pierre. Planificación urbana y neocapitalismo. Geo Crítica. Cuadernos Críticos de Geografía Humana, 1976, año I, nº 6. <http://www.ub.es/geocrit/geo6.htm>

GARNIER, Jean Pierre. Des barbares dans la cité: de la tyrannie du marché à la violence urbaine. Paris: Flammarion, 1996. 381 p.

GARNIER, Jean-Pierre. Une violence éminemment contemporaine. Essais sur la ville, la petite bourgeoisie intellectuelle et l'effacement des classes populaires. Paris: Agone, 2010. 254 p.

GASTAUT, Yvan. Les bidonvilles, lieux d'exclusion et de marginalité en France durant les trente glorieuses. Cahiers de la Méditerranée, 2004, vol. 69,14 p.

<http://cdlm.revues.org/index829.html>.

LEAL, Jesús. Dynamique socio-spatiale récente des grandes villes espagnoles: vers un plus grand déséquilibre. En COLLOQUE 2010 (en publicación).

LÓPEZ LUCIO, Ramón. Sur les nouvelles périphéries. En COLLOQUE 2010 (en publicación).

MONTIEL, Antonio. Aproximación al modelo valenciano de ejecución del planeamiento urbanístico. Sus actores y los impactos observables en los derechos individuales, los recursos naturales y otros bienes colectivos. En COLLOQUE 2010 (en publicación).

MORA ALISEDA, Julián, y Manuel PIMIENTA MUÑIZ. La Estrategia Territorial Europea (ETE). Una concepción integradora y cohesionada del espacio. Norba. Revista de Historia, 1996-2003, vol. 16, p. 701-703.

NAREDO, José Manuel. Anatomía y fisiología de la conurbación madrileña. En VVAA, Madrid, Club de Debates Urbanos. Madrid, Club de debates urbanos, Instituto Juan de Herrera, 2003, pp- 34-52.

NAREDO, José Manuel. La burbuja inmobiliariofinanciera en la coyuntura económica reciente (1985-1995), Madrid: Siglo XXI, 1996. 164 p.

NAREDO, José Manuel. Composición y valor del 
patrimonio inmobiliario en España (1990-1997), Madrid: Ministerio de Fomento, Colección Estudios, 2000. 85 p.

NAREDO, José Manuel. El modelo inmobiliario español y sus consecuencias. En COLLOQUE 2010 (en publicación).

NAREDO, José Manuel, y PARRA, Fernando. Situación diferencial de los recursos naturales españoles. Teguise: Fundación César Manrique, 2002. 340 p.

NAREDO, José Manuel y GUTIÉRREZ, Luis. La incidencia de la especie humana sobre la faz de la Tierra (1955-2005). Granada: Ed. Universidad de Granada/Fundación César Manrique, 2005. 532 p.

NAREDO, José Manuel, MARCOS, C. y CARPINTERO, Óscar. Patrimonio inmobiliario y Balance Nacional de la economía Española (19902004). Madrid: FUNCAS, Colección Ensayos, 2005.

PAREJO, Luciano. Las líneas esenciales de la evolución del sistema legal urbanístico español. En COLLOQUE 2010 (en publicación).

POLLARD, Julie. Promoteurs immobiliers, logiques de marché et régulation des politiques du logement en France et en Espagne (1977-2010). En COLLOQUE 2010 (en publicación)

$\mathrm{ROCH}$, Fernando. El modelo de alojamiento español. Una visión crítica. En COLLOQUE 2010 (en publicación).

SAMBRICIO, Carlos. Cuando se quiso resucitar la arquitectura. Madrid: Colegio Oficial de Aparejadores y Arquitectos Técnicos, 1983. 243 p.

TATJER MIR, Mercedes. El barraquisme a Barcelona al segle XX. En Les barraques de BarceIona. Barcelona: IPEC/Generalitat de Catalunya, 2010 (en publicación).

TATJER MIR, Mercedes. El papel de los investigadores en las políticas urbanas y de su activa participación a través de las redes sociales de carácter vecinal. En COLLOQUE 2010 (en pu- blicación).

TOSCAS, E. Autoridad del Estado y autonomía del municipio en la España liberal. En torno a la incidencia en el territorio de una norma sobre el nombramiento de secretarios municipales (1853-1868). Scripta Nova. Revista Electrónica de Geografía y Ciencias sociales, 2008, vol. XII, núm. 256. <http://www.ub.es/geocrit/sn/sn256.htm>

TOSCAS, E. y AYALA, F. Estado liberal y poder local en España. El papel de las incompatibilidades entre „empleos públicos" en la configuración del moderno secretario municipal: normas y prácticas. Scripta Nova. Revista electrónica de geografía y ciencias sociales, 2003, vol. VII, núm. 154.

<http://www.ub.es/geocrit/sn/sn-154.htm>

VASSET, Philippe. Un livre blanc. Paris: Fayard, 2007. 136 p.

VINUESA, Julio. La construcción de viviendas, el uso del parque residencial y las políticas de vivienda como realidades divergentes en España. En COLLOQUE 2010 (en publicación).

ZOIDO, Florencio. Sur les compétences des diverses administrations territoriales. En COLLOQUE 2010 (en publicación).

\section{Cita del artículo}

CAPEL, Horacio. El urbanismo, la política y la economía (y viceversa). Una perspectiva comparada. Hábitat $y$ Sociedad, 2010, n², p. 155-178.

$<w w w . h a b i t a t y s o c i e d a d . u s . e s>$.

http://dx.doi.org/10.12795/HabitatySociedad.2011.i2.08 